\title{
An Examination of the Performance Based Building Code on the Design of a Commercial Building
}

John P Greenwood (Curtin University of Technology, Perth, Western Australia)

\section{ABSTRACT}

The Building Code of Australia (BCA) is the principal code under which building approvals in Australia are assessed. The BCA adopted performance-based solutions for building approvals in 1996. Performance-based codes are based upon a set of explicit objectives, stated in terms of a hierarchy of requirements beginning with key general objectives. With this in mind, the research presented in this paper aims to analyse the impact of the introduction of the performance-based code within Western Australia to gauge the effect and usefulness of alternative design solutions in commercial construction using a case study project. The research revealed that there are several advantages to the use of alternative designs and that all parties, in general, are in favour of the performance-based building code of Australia. It is suggested that change in the assessment process to streamline the alternative design path is needed for the greater use of the performance-based alternative. With appropriate quality control measures, minor variations to the deemed-to-satisfy provisions could easily be managed by the current and future building surveying profession.

Keywords: Performance based code, Building Code of Australia, commercial building,

\section{INTRODUCTION}

All building development requires an approval to commence prior to construction in order to satisfy the requirements of the Building Code of Australia (BCA). The approval process falls under the heading of building control and is typically administered by a Local Authority Building Surveyor. The control of building construction in Australia has traditionally been through prescriptive regulations (Brannigan et al 1996). Prescriptive codes describe in detail the way in which a building must be built in order to satisfy the minimum requirements set out in regulations (Benge, 1999). In applying the 1990 Building Code of Australia to building development, considerable time and cost was expended by proponents to gain acceptance of alternative building solutions. In the past, many new building ideas were not pursued as it was considered to be easier and less costly to design and construct buildings using traditionally accepted methods.

Established in 1994 the Australian Building Codes Board (ABCB) was a joint initiative of all levels of Australian government, including local government, in cooperation with the building industry. The $A B C B$ maintains and develops the $B C A$. The $A B C B$ also conducts research into the efficiency and effectiveness of building regulatory systems and promotes the introduction of new technology by the building industry. The $A B C B$ was created in recognition that reform of the building regulatory system was necessary to affect extensive savings to the community, industry and all tiers of government. This enhanced reform process required strong senior level commitment from industry and government and a greater level of resourcing from that which already existed. In 1996 the $A B C B$ introduced an alternative method of building control using performance-based criteria (Australian Building Codes Board, 2000). In contrast with prescriptive regulations, performance-based codes describe requirements for health and safety through a set of flexibly defined performance objectives and functional requirements.

The BCA 96 incorporates performance-based building codes and deemed to satisfy provisions (prescriptive codes) which state the technical aspects that buildings and other structures throughout Australia must meet. These provisions cover, among other things, the structure of the building, the fire resistance of building elements and materials, access and egress, services and equipment, health and amenity, and maintenance of services and equipment (Australian Building Codes Board, 2001). It is suggested that the introduction of the BCA 1996 has influenced the way in which building designers have approached the design of construction projects. With this in mind, the research presented in this paper uses a case study to analyse the impact of the introduction of the performance-based code within Western Australia to gauge the effect and usefulness of alternative design solutions in commercial construction. 


\section{TOWARD PERFORMANCE BASED CODES}

Building construction in Australia has traditionally been controlled by prescriptive regulations as enshrined in a controlling document; the BCA. The BCA was introduced to all States and Territories in 1990 and adopted as the sole document that controls the standard of building construction in Australia (Owen and Thomas, 1997). The new Building Code of Australia replaced State controlled Universal Building Bylaws. Each State and Territory had individual and often very different laws to control building construction. Notwithstanding the need to allow for climate variation throughout Australia, the BCA brought about a consistency in construction on a national basis.

The 1990 BCA contained detailed prescriptive requirements on how buildings were to be constructed in order to comply with the BCA. The BCA consists of a collection of minimum construction requirements and standards that describe how buildings should be designed, built, protected and maintained with regard to the health, safety and amenity of the general public (Bukowski,1995), (May, 2003). For the most part, this is accomplished using documents that specify both what is required for health, safety and amenity and how these requirements are to be met (Meacham, 1996). For example, in regards to public assembly buildings, Class $9 \mathrm{~b}$ under the Building Code of Australia 1990 stipulates the maximum travel distance to an open space in the event of a fire. The travel distance is prescriptive but does not take into account the individuality of the building and the extent of the smoke spread within the structure. Thus, if the intended objective of the travel distance restriction is life safety, it would be easy to state that the requirement has been met, but difficult to prove that the objective has been met.

The most serious problem with the prescriptive approach is that it serves as a barrier to innovation (Whittaker et al, 2003). Over time, improved and/or alternative products may be developed, yet their use might not be allowed if construction is governed by prescriptive codes and standards. One example of this is the development of base isolation systems that protect buildings from damage and occupants from life-threatening injury during earthquakes. Widespread application and adoption of these systems soon after they were first developed in the 1960s would have had the potential to save many lives and reduce economic damage from earthquakes. It is indicated that prescriptive code requirements hampered and greatly delayed their adoption (Bergeron, 2002).
Performance-based codes were introduced in Australia in 1996 under an amendment to the BCA to attain the following improvements of a revised building control industry:

- introducing greater flexibility in building design;

- improving the clarity of requirements in building approvals;

- reducing the complexity of the Code, allowing a greater ease of use;

- allowing easier application to renovation and refurbishment projects;

- creating a greater responsiveness to innovation; and

- introducing greater clarity of intent and consistency in scope.

Performance-based codes are a set of explicit objectives, stated in terms of a hierarchy of requirements beginning with general objectives, for example; public health, fire safety or structural adequacy (Deierlein, \& Hamilton, 2003). The requirements then move through more specific objectives including, safeguarding people from injury or illness when evacuating a building on fire (Fielding, 2003). Finally, functional statements are addressed by specific articles within the code, for example building users will have safe egress from a fire in a building via a fire isolated passageway. Thus in contrast to prescriptive regulations, performancebased codes describe requirements for health and safety through a set of flexibly defined performance objectives and functional requirements. Examples include broad statements such as the objective of this:

- section is to safeguard occupants from illness or injury while evacuating in an emergency (BCA 1996:p.10,021) ; and

- part is to prevent the spread of fire between buildings (BCA 1996: p.6,021).

In this case, the solution is not prescribed in the regulations. Rather, it is the responsibility of the designer to demonstrate that the proposed design fulfils the health and safety needs of the community by meeting the functional objectives and performance requirements of the Code (ICC, 2003). The demonstration of compliance can be accomplished through the application of accepted methods, which are either deemed to satisfy (specified) solutions or performancebased design solutions. The performance approach is, in essence, the practice of thinking and working in terms of ends rather than means (Lee et al, 2003). 
Performance-based codes have several advantages over specified methods (Deroukakis, 2000). First, the objectives are clearly stated. Second, the analytical methods, data, and assumptions are formalised in a code of practice, clarifying procedures (Kose, 2003). Third, the former, prescriptive requirements are retained as deemed to satisfy provisions providing continuity and basic methodology for a significant number of projects where a performance analysis may not be warranted (Whittaker et al, 2003). Codes of practice are continually being developed in order to provide guidance on categorising fires, understanding occupant loading and their characteristics, together with other parameters determined through occupancy type. For example, in mercantile occupancy in Australia, several types of fires, numbers of customers (including a mix of disabled) and allowances for staff training and fire department response times are all specified. These are used as design criteria in the same way a structural engineer will use to design loads in documenting a new structure (Bukowski, 1995). Under a performance-code the designer is free to use alternative means to ensure that the building occupants can be safely evacuated. A performance-based code is defined as one that gives the engineering design specifications to be met through identified performance objectives and acceptable calculations (NRC, 2003).

Adopting performance-based design standards using performance-based codes requires a change in attitude and philosophy (Weaver, 2003). Designers may need to consider focusing less on whether a specific fire protection feature should be required. Rather, designers should work toward developing various design standards that indicate performance expectations of a specific feature, such as smoke detection (Heskestad, 2005).

\section{PERFORMANCE BASED THEORY AND APPLICATION}

The theory of performance-based design allows a designer to develop a single design solution that complies with the individual building code requirements in any location and satisfies all approval authorities (Foliente, 2006). The performance-based design theory would allow a single design analysis package for any one task that will be acceptable nearly anywhere in the world regardless of local building materials and by-laws. The concept of performance based codes brings together many of the benefits that established prescriptive codes provide, for example, the certainty of traditional building forms, techniques and materials, with the increased flexibility provided through the mix of use of established performance requirements (Thomas and Bowen, 1996). The defining characteristic of a performance-based system is the replacement of prescriptive requirements with performance objectives and the means to assess whether these objectives will likely be met. Thus, the transition to a performancebased code system would require that society agrees on its objectives for the built environment and on the methods by which performance is to be assessed.

The adoption of a performance only approach would require the rapid development of a considerable number of verification and computational tools and models, which would be necessary in order for designers and building officials to apply such codes. As well, it is argued some code requirements do not lend themselves to a performance-based solution and are better left as prescriptive or specification-type statements (Thomas \& Bowen, 1996). Therefore, a more logical and flexible approach is required. Codes organised around a logical framework that clearly state the intent (objective) of each code requirement and then relate each of these objectives to higher, and subsequently top level, objectives of the code document (in essence the scope of the code) are preferred. Accompanying each of the code requirements would be one or more acceptable solutions (Meacham, 2004). Acceptable solutions can be performance or prescriptive-based. In some cases both kinds of solutions, performance and prescriptive, may be available to address a specific requirement within the code.

The application of performance-based building should enhance consumer-orientation within the building industry, because throughout the building process the explicitly defined user requirements will be the basis for all communication (NRC, 2003). It will therefore lead to buildings that better fit the user requirements (both functionally and in terms of costs).

Under a performance based code design environment, it is expected that not only the use of engineering calculations in design will increase but also more innovation in building designs and associated products will emerge (Meacham, 2004). This will increase the need for standardising performance criteria and the need for developing society-acceptable risk levels. The establishment of criteria and the development of risk assessment models that use both deterministic and probabilistic methods to assess the life risks in buildings from fires will lead to cost-effective and safe fire protection designs (Hua et al, 2000). In addition, the use of 
computer based tools to evaluate compliance with code requirements will succeed if they continue to be validated using full-scale test data and if training programs are designed to educate users on the application of these tools.

Finally, one thing is certain; the introduction of performance-based codes requires a higher level of expertise and knowledge both from the designer and the approval authorities (Hadjisophocleous et al. 1998). In Australia, the performance-based BCA was drafted using several international models including New Zealand, United Kingdom, Sweden and the Netherlands. These systems were adapted to suit the Australian building regulatory environment ( $A B C B, 2004)$. In examining the influence of the performance-based $B C A$ on design solutions for construction projects a case study of a commercial building is undertaken.

\section{CASE STUDY}

Case study research is multi-method in its focus, involving an interpretive, naturalistic approach to its subject matter (Raftery, 1997). This means that case study researchers study things in their natural settings, attempting to make sense of, or interpret, phenomena in terms of the meanings people bring to them. The Case Study Research Method (1997) characterises qualitative research as an umbrella concept covering several forms of inquiry that help to explain the meaning of social phenomena with as little disruption of the natural setting as possible and in which the focus of the study is on interpretation and meaning. Within this framework a case study can be defined as a methodology in terms of the process of actually carrying out the investigation, the unit of analysis (the case) or the end product.

\section{DATA COLLECTION}

Case study data collection is typically multimethod, usually involving interviewing, observing and analysing documents. Multiple sources of information are sought and used because no single source of information provides a comprehensive perspective. By using a combination of observations, interviewing and document analysis, the author was able to use different data sources to validate and crosscheck findings (Jick, 1979). A case study methodology was an appropriate research tool to carry out a practical example of the use of performance-based solutions on a large commercial building development. Participants involved with the design and construction of the project were interviewed and each interview ranged from 30 mins to one hour in length.

\section{CASE DESCRIPTION}

The City of Perth Local Authority encompasses 8.75 square kilometres including the Central Business District (CBD) of Perth. The Planning Scheme incorporates mixed-use development including 2,246 households, 3,123 inner city residential units and $1,271,100 \mathrm{~m}^{2}$ office floor spaces in the CBD (City Vitality Report, 2004). As the major centre for high-rise building in WA, the City of Perth is the focus of commercial development and therefore the most appropriate Local Authority for assessment of the use of performance-based building licence applications in commercial development. The PCEC was selected as case to examine because it was a building that was subject to performance based codes.

The \$220 million Perth Convention Exhibition Centre (PCEC) was designed by a team of Western Australia's leading architects, engineers and builders, including The Cox Group, Arup and Multiplex respectively. The venue's design capitalizes on its unique riverside location, while providing a critical business link direct to Perth's city centre for delegates and visitors. Opened in August 2004, the PCEC centre will generate $\$ 2.2$ billion into WAs economy in its first decade of operation and create 2,600 jobs. The PCEC is centrally located in the heart of the city and can cater for up to 5,000 delegates. The state-of-the-art, three-level venue is WAs only purpose-built convention, exhibition and meeting venue. Its major facilities include a six exhibition pavilions, Riverside Theatre, a 2,500-seat tiered auditorium with 23 specialist meeting rooms, and BelleVue Ballrooms.

\section{VALIDITY AND RELIABILITY}

The PCEC case study draws on all of the aspects of a single case study structure. It explains why certain things were done the way they were; it is descriptive as it narrates the procurement process. The results of some of the areas of research are simply presented in a descriptive manner, there being little in the way of theory with which to compare the data gathered. In addition to contemporaneous documentary evidence the researcher also had access to direct observation and systematic interviewing (Yin, 1984). This method of data gathering was used carefully as the researcher wanted to avoid the possibility of personal bias entering into the research. Such bias is one of the main reasons why case study research lacks credibility (Kumar, 1996). Any direct observations recorded in the text of the report are therefore clearly qualified as such. Therefore by adopting the critical instance case study 
structure the researcher was confident that the data gathered from the personnel working on the PCEC was reliable and valid.

\section{FINDINGS}

Twenty structured interviews were completed during this study (Table 1 ). The position title of the respondent was recorded in order to gain a suitable cross section of building professionals working on the convention centre. This was necessary to attain a wider view of the issues involved with alternative design solutions both during the design and construction phases of building.

\begin{tabular}{|l|c|}
\hline Position of respondent & Number \\
\hline \hline Contractor & 6 \\
\hline Engineer & 4 \\
\hline Project Manager & 2 \\
\hline Quantity Surveyor & 2 \\
\hline Architect/Designer & 3 \\
\hline Building Surveyor & 3 \\
\hline \hline Total & 20 \\
\hline
\end{tabular}

Table 1 Position title of respondent

Respondents were asked to indicate the number of performance-based solutions that they personally had been involved in on this project in order to gauge the respondent's involvement and number of alternative design solutions being used on the case study development (Table 2). $60 \%$ of respondents indicated that they had been involved in seven or more performance-based solutions. This suggests that, due to the nature and design of the PCEC, alternative design solutions were the preferred option to resolve design issues.

\begin{tabular}{|c||l|}
\hline Number of PBS & Number \\
\hline $0-3$ & 3 \\
\hline $4-6$ & 5 \\
\hline 7 or more & 12 \\
\hline \hline
\end{tabular}

Table 2. Number of performance-based solutions

The value of the performance-based solution was identified to determine when an alternative design was employed based on financial reasons. It was revealed, as noted in Table 3, that only design issues over the value of $\$ 100$ 000 are subject to alternative design solutions. Low cost design issues were not pursued through alternative design solutions due to the actual cost of obtaining approval for the variation itself.

\begin{tabular}{|l|c|}
\hline \multicolumn{1}{|c||}{ Typical value } & Number \\
\hline \hline $0.00-\$ 10000$ & 0 \\
\hline$\$ 10000-100000$ & 0 \\
\hline$\$ 100000-\$ 1000000$ & 6 \\
\hline More than $\$ 1000000$ & 14 \\
\hline \hline
\end{tabular}

Table 3. Typical value of a performance-based application

Table 4 identifies the key factors that contributed to the selection a performance based solution. Overwhelmingly the greatest reason, $75 \%$, for employing a performance-based solution design is the cost of the deemed-to-satisfy alternative outlined in the Building Code. Innovation in design followed with 20\%. Therefore, according to this case study, the primary factor in applying alternative design solutions is cost saving. Respondents indicated that the alternative design approach significantly increased approval times. Each respondent was given the opportunity to comment on this question. From the 18 respondents who indicated an increase in time taken, fourteen sighted a major delay to the construction project due to approval difficulties.

\begin{tabular}{|l||c|}
\hline \multicolumn{1}{|c||}{ Reason } & Number \\
\hline \hline Cost of Deemed-to-Satisfy Provision & 15 \\
\hline Innovative Design & 4 \\
\hline Other & 1 \\
\hline \hline
\end{tabular}

Table 4. Reasons for alternative design solution

Construction personnel involved in performancebased design were asked whether they believed there was a significant difference in cost to the client when using alternative design solutions. $75 \%$ of respondents to this question indicated that they believe there was a reduction in cost to the client by the use of performance-based building. Five respondents identified the area of cost saving as a reduction in fire protection whilst the remaining respondents did not comment on 
this aspect. Four respondents (20\%) were not aware of the cost implications of the performance-based solution. Respondents clearly indicated (80\%) that the only reason for applying for alternative design solutions was for financial savings. This analysis suggests that developers are mainly focused on cost savings over innovative design. However, the majority of respondents were in favour of the performancebased building code despite some of the misgivings indicated by early responses to questions posed (85\%).

\section{DISCUSSION}

In order to progress the intentions of a performance-based building code in Australia, it is necessary to identify areas that require attention to streamline the process of alternative design solutions. The case study results clearly show an issue with the approval process of an alternative design and therefore the following recommendations are stated.

Simplify the process of approval for an alternative design proposal

Methods of verification slow the process of approval and increase the cost of an alternative design proposal thus limiting the application of alternative solutions to only situations that cannot be resolved through traditional deemedto-satisfy methods or where the cost of the alternative design is clearly beneficial to the applicant. The use of performance-based solutions in fire safety systems has demonstrated the advantages of employing an alternative design approach. To introduce a system that allows alternative design in areas other than fire safety will increase the value of performance-based solutions even further. Employing methods of comparison through previously accepted design using the experience and professionalism of the building surveyor will significantly increase the use and acceptance of alternative construction in areas other than fire protections systems.

Allow for smaller alternative design proposals to be assessed by the building surveyor

Due to the cost and length of time taken to gain approval for an alternative design, a greater level of delegated authority should be issued to the building surveyor for smaller, non-life threatening alternative proposals. This may be carried out without the need for expensive engineered solutions for what may be a minor deviation to the deemed-to-satisfy provisions of the code. This would allow greater acceptance of the performance-based code for minor construction alternatives.
Provide Defined Legal Boundaries to Limit Litigation where the Duty of Care has Clearly Been Exercised

In considering performance-based building applications, the building surveyor must employ the tools available as prescribed in the code itself. By delegating authority to the certifier to consider applications of a minor nature and indeed to deal with more complex applications in a more professional manner, it is imperative that the legal system allows for sufficient protection under the legislation where a certifier has acted in good faith whilst carrying out an assessment with suitable duty of care. This may be provided by the Local Government Authority or through private certification with the aid of legislation governing the extent of the liability for negligence. Without such reassurance a bureaucracy is established and protracted and expensive approval processed are employed as is currently the case.

\section{Provide competition in the certification market}

With the monopoly of the Local Government approval process the building control industry cannot compete in an open market. All other States and Territories in Australia have adopted private certification for building licence approval. The concept of alternative building design was clearly restrained on the PCEC due to City of Perth Local Council taking longer time than is necessary to issue necessary approvals. It is imperative therefore that the Government of WA introduces a competitive market structure to improve the service to developers who are clearly restrained in their application for alternative design systems due to the length of time to gain approval. Increased understanding of alternative design applications by building surveyors will allow for greater application of performance-based codes. The market forces will eventually improve the service provided by the approval authority as they will act as a consultant in the concept design stage and therefore ensure compliance with the code by the time a formal approval application is submitted.

\section{CONCLUSIONS}

In analysing the data from the case study carried out in this research it apparent that the use of performance-based building in WA is restricted to areas in commercial projects that entail significant cost savings associated with an alternative design application. The cost and difficulty in obtaining an alternative design approval is prohibiting the use of performancebased construction where developers are choosing to use the deemed-to-satisfy solution 
as a means to gain approval. The research revealed that there are advantages to the use of alternative designs and that all parties, in general, are in favour of the performance-based building code of Australia. With these results, a change in the assessment process to streamline the alternative design path will no doubt result in a greater use of the performance-based alternative. With appropriate quality control measures, minor variations to the deemed-to-satisfy provisions could easily be managed by the current and future building surveying profession.

The Government of WA is currently involved in a review of the building control process with the development of a possible future Building Act that may include some form of private certification in-line with the National Competition Policy. Future research could compare the results of a closed market as seen in this study and any future study under an open market certification industry. Alternatively a comparative study carried out in the Eastern States where an open market competition policy has been employed for many years would indicate any differences in the use of performance-based building designs on commercial buildings.

In order to progress the legislation for Building Control in WA, it may be necessary for all construction personnel to support lobby groups to the State Government for action on a new Building Act. The current legislation for building control is forty seven years old and is out of touch with modern day thinking and the rest of Australia. Regardless of whether open competition is adopted there remains scope for further education to both Building Surveyors and associated white collar building professionals on the benefits of using performance-based building applications. Promotion and training courses in this area will benefit the industry as a whole when cooperation is established between all interested parties.

\section{REFERENCES}

Australian Building Codes Board (1996) Building Code of Australia Volume $1 \& 2$

Benge, Claire (1999) Dealing with alternative construction methods through performance based building codes, paper for the $2^{\text {nd }}$ international Conference on construction Industry Development, and the $1^{\text {st }}$ Conference of CIB TG29 on construction in Developing Countries, retrieved 14 January, 2004, from http:/www.ecobuildnetwork.org.chchost.com/eng 3.htm

Bergeron, D. (2002) Role of acceptable solutions in evaluation innovative designs in Proceedings of the $4^{\text {th }}$ International conference on performance-based codes and fire safety design methods, SFPE, Bethesda, MD.

Brannigan, Vincent JD and Meeks, Carol B (1996) Performance Based Codes: Economic Efficiency and Distributional Equity in Conference Proceedings Interflam '96, Interscience Communications, London, pp573580

Bukowski, RW (1995) International Activities for Developing Performance-Based Fire Codes Fire Safety Design of Buildings and Fire Safety Engineering Proceeding of the Mini-Symposium, Tsukuba, Japan, IV, pp25-27

Bukowski, RW (1996) Risk and Performance Standards in Fire Risk and Hazard Assessment Symposium: Research and Practice: Bridging the Gap Proceedings, National Fire Protection Research Foundation. June 26-28, 1996, San Francisco, CA, pp37-45, and U.S./Japan Government Cooperative Program on Natural Resources UJNR Fire Research and Safety 13th Joint Panel Meeting, vol 1, 13-20 March, Gaithersburg, MD, Beall, KA (ed) pp79-88

Deierlein, G.G. and Hamilton, S. (2003) Framework for structural fire engineering and design methods, Invited white paper at the NISTSFPE workshop on National R\&D Roadmap for fire safety design and retrofit of structures, 2-3 October 2003, Baltimore, MD

Deroukakis, Eleni, (2000) Performance-based codes impact on international trade, Occasional Paper for Inter-Jurisdictional Regulatory Collaboration Committee, retrieved from http://www.ircc.gov.au/

Foliente, G (2006) The Performance Concept, performance-based building $R \& D$ roadmap towards Europe's vision 2030 for construction, CSIRO

Fielding, G, (2003) Changing demographics, disability access and the use of performancebased design, Invited Paper at the Global Policy Summit on the Role of Performance-based International Policy and Local Needs, National Academy academics.org/bice/global_policy_summit_2003. html.

Heskestad, Atle (2000) Practical Experiences on a Systematic Method of Assessing Level of Fire Safety by Evaluating both Organizational and Technical Fire Protection Measures presented at 3rd International Conference on PerformanceBased Codes and Fire Safety Design Methods retrieved from http://www.brand.Ith.se/PBDConf/ 
Hua, Jinsong and Khoo, Boo Cheong, (2000) Application of unstructured CFD method in performance based building fire safety design presented at 3rd International Conference on Performance-Based Codes and Fire Safety Design Methods retrieved from http://www.brand.Ith.se/PBDConf/

ICC (2003) Performance Code for Buildings and Facilities, International Code Council, Falls Church, VA.

Jick, DT 1979, 'Mixing Qualitative and Quantitative Methods: Triangulation in Action', Administrative Science Quarterly, vol. 24, no. 4, pp. 602-11.

Kose, S. (2003) The impact of rapid ageing in Japan on accessibility issues, Invited Paper at the Global Policy Summit on the Role of Performance-based Building Regulations in Addressing Societal Expectations, International policy and local needs, National Academy of Sciences, Washington DC.

Kumar, R. (1998). Research Methodology: A Step by Step Guide for Beginners. Melbourne: Addison Wesley Longman Australia Pty Limited,

Lee, Angela and Barrett, Peter (Eds) (2003) Performance Based Building: First International State-of-the-Art Report by the International Council for Research and Innovation in Building and Construction, Netherlands, retrieved from http://www.pebbu.nl/resources/pebbupublication $\underline{\mathrm{s}}$

May, P.J. (2003) Performance-based regulation and regulatory regimes: the saga of leaky buildings, Law and Policy, 25(4), 381-401.

Meacham, B.J. (2004) Performance-based building regulatory systems: structure, hierarchy and linkages, journal of the structural Engineering Society of New Zealand, 17(1), 3735

Meacham, Brian J. (1996). Concepts of a Performance-based Building Regulatory System for the United States. A paper delivered at the Fire Safety Science, Boston USA.

NCR (2003) ISC Security Criteria for New Federal Office Building and Major Renovation Projects: A Review and Commentary, national Academics Press, Washington Dc

Owen, RP and Thomas, JR (1997) Objectivebased codes: the Canadian direction presented at International Conference on PerformanceBased Codes and Fire Safety Design Methods, Canada, 1996

Raftery, J 1997, 'Breaking up methodological monopolies: a multi-paradigm approach to construction management research', Construction Management and Economics, vol. 15, pp. 291-7.

Thomas, R, and Bowen R. (1996). Objectivebased codes: the Canadian direction. A paper delivered at the International Conference on Performance-Based Codes and Fire Safety Design Methods, Ottawa, Ontario, Canada.

The case study as research method (1997) retrieved 6 May, 2004, from http://www.gslis.utexas.edu/ ssoy/usesusers/13 91d1b.htm

Weaver, E.A. (2003) Three useful tools for goal setting: judgement analysis, the Taylor-Russell diagram and the System Dynamics Model, Invited Paper at the Global Policy Summit on the Role of performance-based building regulations in addressing societal expectations, International policy and local needs, National Academy of Sciences, Washington DC (available at: National Academy academics.org/bice/global_policy_summit_2003. html.

Yin, K. R. (1984) Case Study Research, Design and Methods, Sage Publishing, London, England, United Kingdom 